\title{
The Caucasus Territory Hot-Cold Spots Determination and Description Using 2D Surface Waves Tomography
}

Seyed Hossein Abrehdari ( $\square$ abrehdari@ut.ac.ir )

National Academy of Science

Jon K. Karapetyan

Institute of Geophysics and Engineering Seismology, National Academy of Science

Habib Rahimi

Institute of Geophysics, University of Tehran

Eduard Gyodakyan

Institute of Geophysics and Engineering Seismology, National Academy of Science

\section{Research Article}

Keywords: Caucasus area, Hot-Cold spots determination, Renewable energy resources (geothermal), 2D surface wave tomography, Single-Station method

Posted Date: July 26th, 2021

DOl: https://doi.org/10.21203/rs.3.rs-700822/v1

License: (9) This work is licensed under a Creative Commons Attribution 4.0 International License. Read Full License 


\title{
The Caucasus Territory Hot-Cold Spots Determination and Description Using 2D Surface Waves Tomography
}

\author{
Seyed Hossein Abrehdari ${ }^{1,2 \boxminus}$, Jon K. Karapetyan ${ }^{3}$, Habib Rahimi ${ }^{4}$, Eduard Gyodakyan ${ }^{3}$ \\ 1. PhD Student, Institute of Geophysics and Engineering Seismology, National Academy of Science; Gyumri, \\ Republic of Armenia \\ 2. Seismology Research Division, Institute of Geophysics, University of Tehran; Tehran, Iran \\ 3. Candidate of Geol. Sci., Institute of Geophysics and Engineering Seismology, National Academy of Science; \\ Gyumri, Republic of Armenia \\ 4. Associate Professor, Department of Earth Physics, Institute of Geophysics, University of Tehran; Tehran, Iran \\ $\square$ e-mail: abrehdari@ut.ac.ir
}

\begin{abstract}
Many questions have been raised about the thermal-mechanical development of faults movement, passive margins based on the effects of plate-boundary interactions, lithospheric processes, and mantle activity, in addition to continental thinning and generally the heat beneath our feet. This study attempts to identify and describe the hot-cold spots deep inside the Earth by using the 2D tomography velocity images obtained from surface wave seismic interferometry and regional tectonic activities in different geological units of the Caucasus region continentcontinent ongoing collisional-compressed edge of the Eurasian-Arabic plates. Furthermore, this study could be helpful in identifying and proper understanding of the location of hotspots as renewable energy resources (geothermal) in areas near tectonic plate boundaries, rocks, arcs, and sediment interactions. To conduct this, after the preliminary correction of the raw data, a generalized 2D linear inversion procedure has been applied to construct the surface wave tomography to generate group velocity maps in a period range of 5-70 seconds and grid spacing of $0.2^{\circ} \times 0.5^{\circ}$. The digital records of 800 earthquakes $(M \geq 4)$ have been collected over the Caucasus region and these signals, recorded during the period of 1999-2018, come from 45 three-component broadband and short-period digital stations.
\end{abstract}

Keywords: Caucasus area, Hot-Cold spots determination, Renewable energy resources (geothermal), 2D surface wave tomography, Single-Station method

\section{Introduction}

Nowadays, the development of image fusion methods in the image visualization approach with higher spectral information from within the human body and objects and inside the earth is a very beneficial achievement. According to the seismic tomography images hypothesis from within the earth, the dark blue and dark green shades mean colder and stiffer rock (Cold Spots) and red shades mean warmer and weaker regions (Hot Spots) and green and yellow color and almost green-blue, are the remnants of an old tectonic plate that has been subducted underneath the Earth plates (large cold and aseismic area during million years). Geologists believe that a hotspot is a location on the Earth's surface that has experienced active volcanism for a long period of time and the places known as hotspots or hot spots are volcanic regions thought to be fed by underlying mantle that is anomalously hot compared with the surrounding mantle.

The origins of the concept of hotspots lie in the work of Wilson, J. Tuzo (1963), who postulated that the formation of the Hotspot is from the slow movement of a tectonic plate across a hot region beneath the surface. It was later postulated that hotspots are fed by columns or narrow streams of magma or hot mantle rising from the Earth's core-mantle boundary in a structure 
called a mantle plume. Athough, USGS (1999) reported that whether or not such mantle plumes exist is the subject of a major controversy in Earth science. It is estimated that the number of hotspots which are fed by the Earth's mantle plumes has increased from 20 to several thousand in recent years. For example, the Hawaii, Réunion, Yellowstone, Galápagos, and Iceland are some of the most active volcanic regions to which the hypothesis is applied (Fig. S1). Subduction zone volcanoes, where water is trapped beneath the main plate, have violent eruptions. These violent eruptions are due to the intense power of water vapor, which is the result of the melted basalt megam in the form of rhyolites. In comparison with island arc volcanoes; when one oceanic plate collides with another, the denser plate is forced downward into a deep ocean trench. This plate, as it is subducted, releases water into the base of the over-riding plate, and this water mixes with the rock, thus changing its composition causing some rock to melt and rise and this is where a chain of volcanoes is strengthened and regenerated. While, in hotspot volcanic chains, the joint mantle plume-hotspot hypothesis predicts that time-progressive chains of volcanoes are developed on the surface (e.g. Yellowstone and Hawaii; Fig. S1). So, a hot spot develops above the plume and magma generated by the hot spot rises through the rigid plates of the lithosphere and produces active volcanoes at the Earth's surface. As oceanic volcanoes move away from the hot spot, they cool and subside, producing older islands, atolls, and seamounts. As continental volcanoes move away from the hot spots, they cool, subside, and become extinct.

Dye, S. T. (2012) says that the geothermal energy is the thermal energy in the Earth's crust which originates from the formation of the planet and from radioactive decay of materials in currently uncertain but possibly roughly equal proportions. Figs. S8 and S9 related with Positron generation-annihilation and physical processes of the generation of magma inside the Earth, respectively; that lead to the geothermal energy and two annihilation photons or gamma photons (high thermal energy). These figures and Dye (2012) nutshell have the same concept. Geothermal heating system is very useful for human life, for example using water from hot springs (e.g. Ardabil proviance in NW Iran, Turkey, and Icelandic homes) has been used for bathing since Paleolithic times and for space heating since ancient Roman times. The chemical interactions, high temperature and pressure in Earth's interior cause some rock to melt and solid mantle to behave plastically, resulting in parts of the mantle convecting upward since it is lighter than the surrounding rock. However, keep in mind these are just theories and nobody really knows the answer. The honest answer is that lots of folks are working on it but haven't come up with the answer yet.

This study could be usful for identifying the geothermal mechanisms and accurate and efficient approach geothermal resources as a proper understanding of a renewable energy source in areas near tectonic plate boundaries, rocks, arcs and sediments as geothermal or hotspot. It is estimated that the earth's geothermal resources are theoretically more than adequate to supply humanity's energy needs, although only a very small fraction is currently being profitably exploited, often in areas near tectonic plate boundaries. This type of energy is often used in power generation technology, including dry steam power plants, liquid steam conversion power plants, and dualcycle power plants to fuel industrial power plants and urban hot water. As well as, the study benefits from new permanent stations installed in Turkey, Azerbaijan, Georgia, Armenia and NW Iranwhich provide much better coverage in the Caucasus.

In this paper, by using the surface waves seismic interferometry, were successfully illustrated the first 2D surface waves tomography maps along with the averaging area, stretching and data density maps for study area for periods of 5 to 70 seconds and an approximately depth of $200 \mathrm{~km}$ across the Caucasus-Georgia territory by using local-regional earthquake data. Also, the study 
benefits from new permanent stations installed in NW Iran, Turkey, Azerbaijan and Georgia, which provide much better coverage in the Caucasus region. Furthermore, using Depth-Velocity curve was determined the approximate depth of Moho, LAB, LVZ discontinuities and the table of the RGB color model information (color palette table) used in velocity tomography maps of our study (table 2). These maps show excellent agreement with results of previous studies and many of the geological features of the Caucasus territory.

\section{Tectonic setting of the Caucasus}

The Caucasus region, is an orogenic belt that was uplifted as a sequence of the collision and the continuing convergence of the Arabian-Eurasian plates. This area is situated between the Caspian Sea, the eastern Black Sea, the Greater Caucasus, the Lesser Caucasus, the eastern Anatolia and a part of the northwestern of the Zagros Mountains (Figs.1 and 2(a)). In this enigmatic region, there are several basins such as Kura, South Caspian, Rioni, Aras, Alazani, and Kartli. The Rioni Basin in the west and the Kura Basin in the east which dissect this orogenic belt into two parts separating the Greater Caucasus in the north from the Lesser Caucasus in the south and these two basins are separated by the Transcaucasian Dzirula Massif in the middle. According to some studies (e.g. Sosson et al., 1977; Alik Ismail-Zadeh et al., 2020), the Caucasus ranges incload the Greater Caucasus, is consisting mostly of Paleozoic metasedimentary rocks and granitoids, Jurassic sediments, Mesozoic and Cenozoic volcanism and the Lesser Caucasus consist Paleozoic granitoid metamorphic basement overlain unconformably by shelf carbonates of Paleozoic Triassic age, respectively.

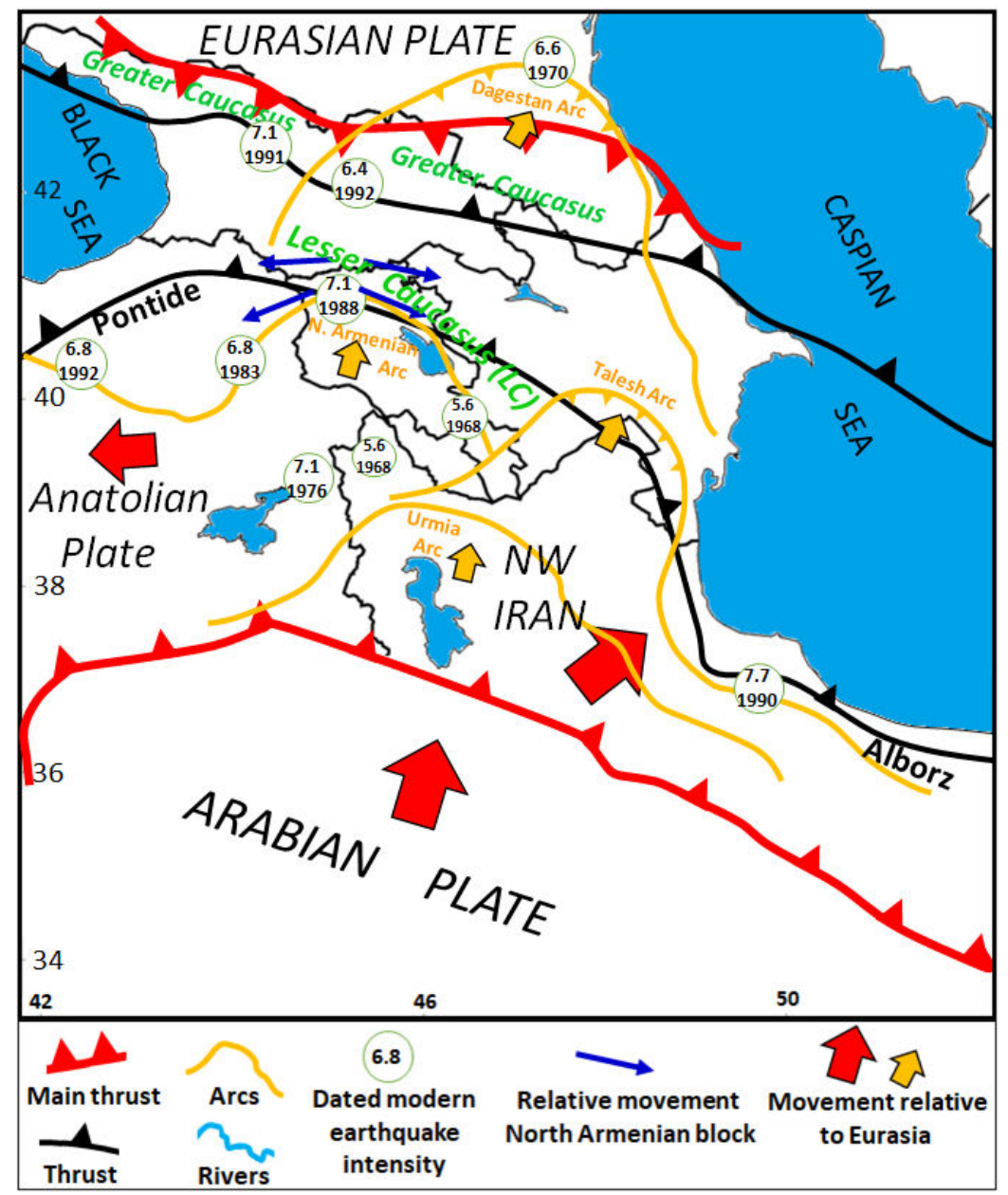

Fig. 1 Active tectonic features of the collision zone of the Central Eurasian-Arabian plates and main Arcs.

Caucasus is compressed between Arabian-Eurasian plates and and due to N-S compression, the main seismoactive structures in NW Iran, Azerbaijan, Georgia, Armenia (Lesser Caucasus), Transcaucasus, NE and E of Turkey and southern parts of Western Georgia or North of Kars in EAAC (Eastern Anatolian Accretionary Complex) are NE-SW left-lateral strike-slip faults and 
major Right-lateral strike-slip faults, major thrust due to intercaucasian collision or the relative movement of the Arabian plate against the Eurasian plate, the fault zones have developed.

In this enigmatic area, there are cmplicated geological structures and large volcanic complexes including Elbrus, Shakhara, Kazbek, Ararat, Aragats, Bazarduzu, Yanardag, Kars, Vedi, Gegham, and etc., which have elevations over $5 \mathrm{~km}$ above sea level. The continuing convergence in the region continues to affect the deformation, tectonic structure, and seismicity of the region. Further details regarding the tectonic setting of the Caucasus and large magnitude earthquakes occurred in the area are described in our supplementary Information and Mcclusky et al. (2000), Youshun Sun et al. (2012), and Jackson et al. (2002) studies. Main arcs in Fig. 1 or Fig. s2 are responsible of the many large earthquakes in the Caucasus. Therefore, the arcs can be considered as a hot structure with high tectonic activities.

\section{Data and Methods}

\section{1 Data-measurements and Raypaths distribution-density}

The study area is located (situated) between $38^{\circ}-54^{\circ}$ degrees east and $37^{\circ}-45^{\circ}$ degrees north (Fig. 2 (a) or $2 \mathrm{~S})$ and approximately were used 30000 vertical (Z) components of surface waves motion and the path between stations (Fig. 3 (b)). In this study, as mentioned; a single-station method was used, and the recorded local and regional earthquakes data with magnitude in 45 threecomponent broadband and shortperiod Seismic Network Incorporated Research Institutions for Seismology (IRIS) stations including Armenia (GNI), Georgia (GO), Turkey) (TK, TU), and Azerbaijan (AB) was used as the primary database during the period 1999 to 2018. Events or earthquake data recorded by the Iranian Seismological Center-Tabriz Network, International Institute of Earthquake Engineering and Seismology (IIEES) have also been used (Table 1 in supplementary file).

Fig. 2 (a) Geological units discussed in the interpretation of two-dimensional (a)
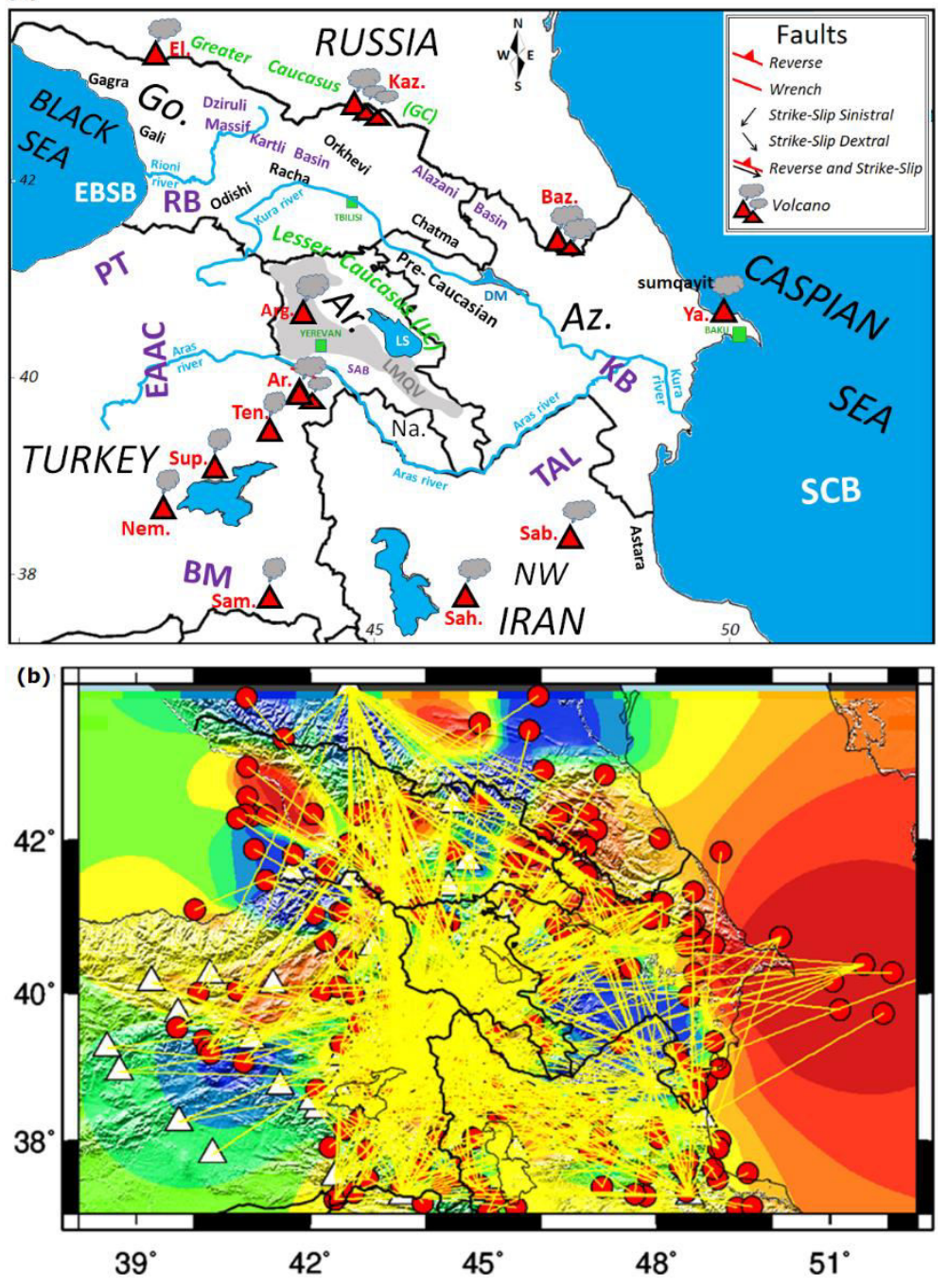

tomography maps of the study area. Major lithospheric structures and volcanic mountains, etc.: Sab. = 
Sabalan, Sah. $=$ Sahand, Samd. $=$ Samadi, Nem. $=$ Namrout, Sup. $=$ Suphan, Ten. $=$ Tendourek, Ara. $=$ Ararat, $\mathbf{P T}=$ Pontide, $\mathbf{B M}=$ Bitlis Massif, EAAC $=$ East Anatolian Accretionary Complex Arag. = Aragats, Sam. $=$ Samsari, El. $=$ Elbrus, Kaz. $=$ Kazbek, Ya. $=$ Yanardag, Rio. $=$ Rioni, Sp. $=$ Spitak, SAB $=$ South Armenia Block, Na. $=$ Nakhchivan, Go. $=$ Georgia, $\mathbf{T C M}=$ Trans Caucasus Massif, Ar. $=$ Armenia, Az.= Azerbaijan, LV = Lake Van, LU = Lake Urmia, LS = Lake Sevan, MD = Mingachevir Dam, SCB = South Caspian Basin, BSB= Blake Sea Basin and LMQV = Late Miocene-Quaternary Volcanic. (b) Sample of the distribution raypaths, events and stations used in this study for the period of 10 seconds (white tringles = seismic stations, yellow lines $=$ raypaths and red circles $=$ earthquake epicenter.

In processing using the single-station method and Yanovskaya-Ditmar 2D linear inversion procedure to estimate group velocity dispersion curves, we used Multiple Filter Technique (MFT) and Time Variable Technique (TVF) to separate the fundamental mode of earthquake data waveform energy. For this purpose, first, the fundamental mode of the Rayleigh surface waves group velocity dispersion curves was separated using Hermann's software, the do_mft command for various source-station paths and by using GSAC, GMT software, and computer specialized codes in Ubuntu software operating system and MATLAB software, twodimensional tomography group velocity, stretching area, data density and averaging area maps were plotted and estimated for periods of 5-70 seconds (Fig. S7).

\subsection{Ray path distribution and density}

The resolution of the group velocity maps depends mostly on the density of paths and their azimuthal distribution (crossing paths). In our case, these two parameters depend on the geometry of the seismic array and on the distribution of the earthquakes that can limit the number of available paths for some directions (Fig. 2 (b)).
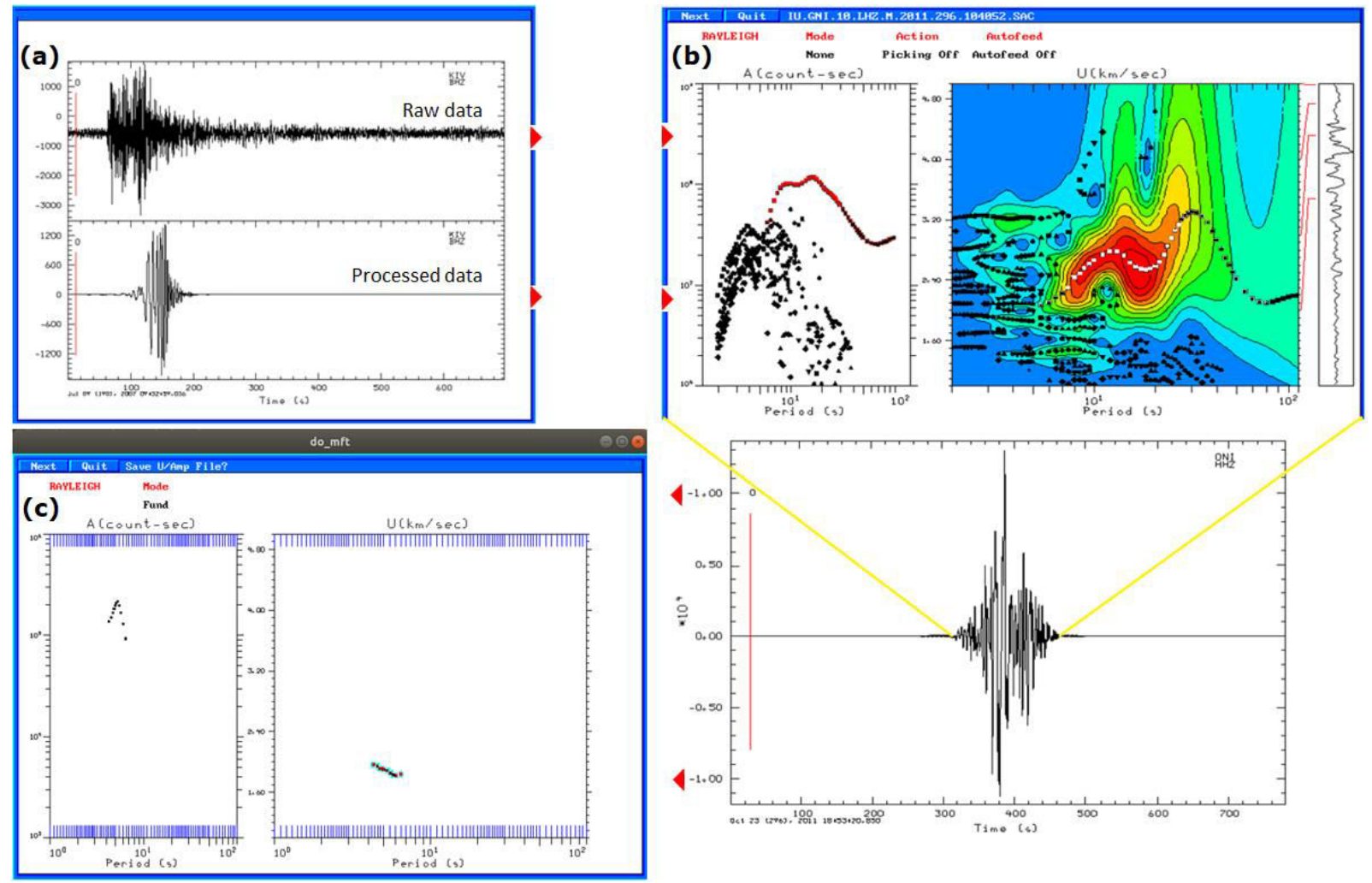
Fig. 3 (a) Raw seismograph and the cleaned waveform (b) fundamental mode of the Rayleigh wave (c) dispersion curve of cleaned waveform processed by Hermann do_mft command of the vertical (z) component recorded by the GNI (Garni) station.

Figure 3(a) shows the raw seismograph and the cleaned waveform and 3(c) shows a sample of dispersion curve processing. More information has given in the caption and on the images. Also, figures S4, S5, and S6 are relevant with data-measurements and ray paths distribution, which depicted with the better resolution in the supplementary file.

\subsection{Two-dimensional surface wave tomography}

Seismic tomography is like taking a Computed Tomography CAT scan of the Earth. In a method similar to CT scans, scientists instead use seismic waves to make images of Earth's interior. When the ground jolts at the start of an earthquake, seismic waves race outwards from it (Kinahan P, Townsend D., 1998). The velocity or the movement of the waves depends on the type of material passing through them. Waves travel faster through cold-rigid material (like a subduction plate inside the mantle) and pass through warmer materials more slowly (like hot rocks rising to the surface). In this study, a 2D-linear inversion method developed by Ditmar and Yanovskaya (1987) and Yanovskaya and Ditmar (1990) has been used to generate the group velocity maps. This method is a generalization of the classical 1D method of Backus and Gilbert (1968). The tomographic method estimates a group velocity map $\mathrm{U}(\mathrm{x})$ at each period by minimizing the following misfit function (Lihua Fang et al., 2008):

$\alpha \iint\left|\nabla_{m}(x, y)\right|^{2} d x d y+(d-G m)^{T}(d-G m)=\min$

Where

$m(x)=(U)^{-1}\left(U_{0}^{-1}\right) \mathrm{U}_{0}$

Where

$d_{i}=t_{i}-t_{i 0}$

$(\mathrm{Gm})_{i}=\iint \mathrm{G}_{i}(x) d x=\int_{l_{o i}} m(x) \frac{d s}{\mathrm{U}_{0}}$

$\iint \mathrm{G}_{i}(x) d x=\int_{l_{o i}} \frac{d s}{\mathrm{U}_{0}}=\mathrm{t}_{i 0}$

Two-dimensional surface wave tomography images corresponding to the period of 5 to $70 \mathrm{~s}$ are depicted in supplementary file Figure S7.

\subsubsection{Physical processes inside the Earth for better understanding of hot-cold spots}

Hotspots and related structures in the mantle to understand the dynamics of Earth and the modes of heat transfer inside the planet are very important and evidence for subduction (underplating) crust in those regions. In Fig. S9, according to the physical processes inside the Earth that lead to the generation of magma, spots or cold areas can follow steps A and D. But from a tomographic point of view, blue and green dark shades mean colder and stiffer rock (coldspots) or Green and Yellow color and almost green-blue, are the remnants of an old tectonic plate that has been subducted underneath the Earth plates (large cold and aseismic area during million years (Fig. S7). Further details regarding the physical processes inside the Earth for a better understanding of hot-cold spots and colors origin in tomography images or color palette tables (CPT) are described in the supplementary information file.

\section{Results and discussion}




\subsection{Hot-Cold determination and description using tomography maps in period 5 to 70 seconds}

As mentioned earlier, according to the seismic tomography images results of the Earth's upper mantle: (1) Blue and green shades mean colder and stiffer rock (Cold Spots) (2) Red shades mean warmer and weaker regions (Hot Spots) (3) the Green and Yellow shape and almost greenblue are the remnants of an old tectonic plate that has been subducted underneath the Earth plates (large cold and aseismic area during millions of years).

In short-periods of 5 to $30 \mathrm{~s}$ (equivalent to a depth of 6 to $68 \mathrm{~km}$ ), the depths, known as the crust (part A of Fig. S9), include soil, vegetation growth, construction, surface and groundwater, oil and gas resources, magma chambers, metallic and non-metallic mines, and chemical interactions, and from this depth, it goes into the Moho-lithosphere-aesthenosphere and upper mantle that is the source of volcanic lava and the origin of some earthquakes in the mantle and remnants of the old tectonic plate. Short-periods of 5 to $30 \mathrm{~s}$ can be considered temporary and unstable hot and cold spots. Dark red stains that are seen below the chain volcanoes (chain volcanoes of Eastern Turkey, volcanoes of the Lesser Caucasus, especially Mount Aragats, Southern Caspian Sea basin, Kura basin and eastern basin of the Black Sea, East of Lake Sevan, Garni town, south of Yerevan and Sahand volcano) indicate the Hot Spots. These spots can include melt, magma, gas plumes, chemical interactions of hydrocarbons, and thick sediments (temporary and unstable hotspots). The rest of the areas on the tomography maps with various periods that have shown with shades and colors bold blue, light blue, blue-green, and green, include colder and more rigid rocks and stones and remnants of an old tectonic plate and are quiet (aseismic), which represent Coldspots (darker blue).

Hotspot number 1 (Fig. 4): There are eight hotspots in the period of 5 seconds that Hotspot number 1 in our study, there is a small area near Kars Mountain in northeastern Turkey known as the Erzurum-Kars Volcanic Plateau (EKVP)- with an approximate depth $6.6 \mathrm{~km}$. This part of the plateau is known to have been formed by the eruptions during the Zanclean ( 4.5 Ma) period, related to an earlier continental collision event between the Eurasian and Arabian continents $\sim 15$ $\mathrm{Ma}$ ago. The depth of this hotspot is about $6 \mathrm{~km}$. Also, Eastern Anatolia is known for its thin lithosphere.

Hotspot number 2 (Fig. 4) is approximately located on the northern slope of Mount Aragats (with an approximate depth of $8 \mathrm{~km}$ ), which could be the reason for the magma chamber. The Aragats center, one of the largest Quaternary volcanic centers in the Caucasus, is confined to the Aragats neovolcanic area in the western part of Armenia, at the intersection of tectonic zones of a general Caucasian extension and the sublongitudinal Transcaucasus uplift. Aragats occupies a special place in the neovolcanic evolution of Armenia in terms of diversity of the magmatic rocks, scales, and duration of volcanism, variety of the eruption products, and intricacy of the geotectonic structure.

In our study, hotspot number 3 (Fig. 4) covers a wide area such as Garni, Shoraghbyur, Yerevan, Avan salt dome, and Harazdan from oil and gas resources introduced by R. Jrbashyan et al. (2001). The Paleocene and Lower Eocene of the subthrust section yielded oil-saturated cuttings, and oil-cut mud and oil-stained cuttings were reported as features of the upper Eocene section in these areas. About this hotspot, a detailed explanation is given as Sevan and Central Troughs by Milanovski, E.E., (1962). Due to the chemical interactions of in-earth materials in oil-rich areas (contains hydrocarbons) and gas resources, the temperature inside the Earth is high, and spots relevant with gas plumes are anomalously hot compared to the surrounding. The depth of this hot zone varies from 6 to $7.6 \mathrm{~km}$. 
Hotspot number 4 (Fig. 4) approximately is located in the beneath of Ararat strato-volcanic structures (depth $\sim 7 \mathrm{~km}$, velocity $2 \mathrm{~km} / \mathrm{s}$ ) in the Julfa region, which could be due to the presence of a magma chamber beneath this volcanic complex. The Ararat volcanic complex and its hot magma could be the best reason for the presence of this hotspot. East-north foothills of this volcanic complex are affected by sediments of Aras river, which is limited by the uplifted basement of the Great-Lesser Ararat volcano to the south and by the Hrazdan Transverse Fault Zone to the west. Also, Ozgür Karaoğlu (2017) seismic tomography study, indicates a magma reservoir at great depths $(20-30 \mathrm{~km})$ below the Ararat volcano. Geochemical constraints on some of the later-formed rocks suggest an interaction between a shallow chamber $(8-10 \mathrm{~km}$ depth) and the deep reservoir approximately $0.5 \mathrm{Ma}$. This is consistent with the result of our study in period of 5 seconds (depth of 7-13 km; Fig. 4 or Fig. S10, T=5s).

Hotspot number 5 (Fig. 4) approximately is located in the northeast of the Lake Van includes Tendürek, Süphan and Nemrut Mountains. Collision related to Quaternary Mafic Volcanism to the north of Lake Van (Eastern Anatolia, Turkey) has been occurred by eruptions from both volcanic centers and extensional fissures trending approximately north-south. We infer, that perhaps, the molten material beneath the Mounts Ararat and the mountains around Lake Van are quite interconnected. Study of Vural Oyan et al. (2017), shows the volcanic products in this area consist of mildly alkaline lavas and calculations based on crustal temperatures and Curie point depths indicate that the magma chamber might have been located at a depth of around 6-8 km, within the upper crust. In the period of 5 seconds in our study, this property has been shown at a depth of 6 to $9.5 \mathrm{~km}$, which is consistent with Vural Oyan et al. (2017) study. As well as, the pattern of concepts is approximately similar in hotspots number 4 and 5 . 

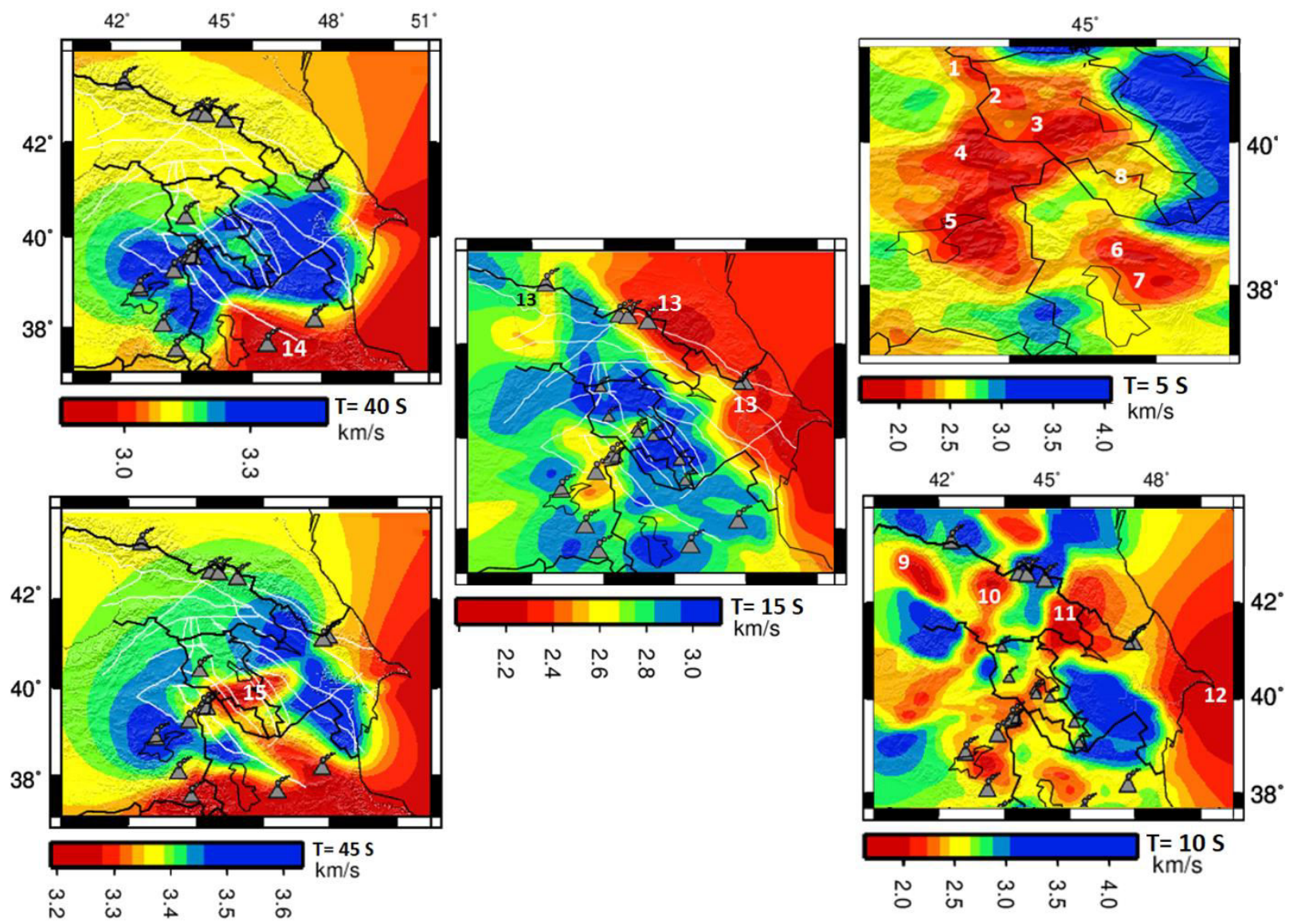

Fig. 4 Rayleigh wave group velocity tomography maps and hotspots (the numbered dark red areas) for periods $5,10,15,40$, and 45 seconds.

Hotspots number 6 and 7 (Fig. 4) are located in NW Iran near the north part of Sahand volcano and southeastern segment of the Tabriz fault. It is clear that these hot spots are due to the interactions of the rocks of this famous and active fault. In a study, Aghazadeh et al. (2010) has reported volcanic eruptions evidences in the South of the Tabriz fault, in the Sahand block. Our results for the lower periods show distinct velocity anomalies along the North Tabriz Fault (NTF) and beneath the Sahand and Sabalan Volcanoes. Also, beneath the Sahand Volcano a high velocity zone is observed that could be due to a low temperature volcanic rocks or a deeper magma chamber.

Hot spot number 8 (Fig. 4) is approximately located near the Salvard fault segment in the northeast of Nakhichevan (Azerbaijan). Exposures of Jurassic sequences are located in Nakhichevan and in Iran, where a $500 \mathrm{~m}$-thick Lower and Middle Jurassic sedimentary sequence overlies Upper Triassic strata. Upper Devonian (the fourth period of the Paleozoic era) and Permian (the fifth period of the Paleozoic era) rocks could be petroleum source rocks (Sosson and others, 2010). Silurian and Lower and Middle Devonian marine clastic and carbonate rocks crop out in Nakhichevan and are presumed to be present in Armenia. Our study in period 5 seconds has shown this property at a 6 to $9.5 \mathrm{~km}$ (hotspot number 8). Therefore, hotspots number 1 to 8 with an approximate depth of 6 to $13 \mathrm{~km}$ are important because are included major discontinuity such as Moho, various chemical materials such as hydrocarbons, Sima, Sial, plagioclase feldspar, ultramafic cumulates, and harzburgites, dense (mafic) iron 
magnesium silicate igneous rocks and basalt. The rest of the blue and green shades imply colder and stiffer rock or Cold Spots (dark blue and green-blue).

Hotspots number 9, 10, 11, and 12 (Fig. 4): In the period of 10 seconds, in addition to the lowvelocity anomaly during the period of 5-second, areas such as the Eastern Black Sea Basin, a segment of the Odishi fault in the Rioni basin (number 9), the Nalchik city in Russia and north and southwestern of Kazbek volcano (number 10), the Chatma region in the east of Georgia (number 11) and South Caspian Basin (number 12) are also covered by the low-speed anomaly, and it follows the same pattern described for the 5 second period. The low-velocity anomaly beneath the volcanoes in depth associated with this period reveals the presence of magma and the magmatic reservoir, and the approximate depth of these hotspots is $20 \mathrm{~km}$.

Hotspots number 13 (Fig. 4): In period 15-second, in addition to the low-velocity anomalies during the 10-second period, the Elbrus, Kazbek, and Yanardag volcanic complexes in the great Caucasus is also covered by the low-velocity anomaly, and the rest of the hotspots in the 15second period follows the same pattern described in the 10 -second period. The low-velocity anomaly beneath the volcanoes in depth associated with this period reveals the presence of magma and the magmatic reservoir, and the depth of these hotspots is $\sim 23 \mathrm{~km}$. We infer that the hot and low-velocity regions of the South Caspian Basin and the Eastern Black Sea are affected by thick sediments.

In the period of 35 to 50 seconds (Fig. S7), the group velocity map shows lateral changes of 2.7 and $3.6 \mathrm{~km} / \mathrm{s}$, and waves are primarily sensitive to depths between 63 and $84 \mathrm{~km}$; namely, the lower crust velocity, the crust thickness, and the uppermost mantle velocity and the average depth is $73.5 \mathrm{~km}$ and has been transferred to the lithosphere layer onset regions. Medium periods of 35 to 50 seconds (equivalent to a depth of 65 to $167 \mathrm{~km}$ ) can be considered temporary and semi-stable hot and cold spots.

Hotspot number 14 (Fig. 4): In the period 40 seconds, we see a large hotspot area with lowvelocity (approximately $2.8 \mathrm{~km} / \mathrm{s}$ ) in the Southern Caspian Basin (SCB) below the Sahand and Sabalan Mountains, the Tabriz Fault, and slightly in the southernmost mountain around Lake Van (LV) or Bitlis Massif (BM) at Iraq border, which the mid-lithosphere magma source has a distinct composition compared with the base of the lithosphere, that is argued to be the result of the increased retention of metasomatic components in phases such as apatite and amphibole, which are stabilized by lower temperatures prior to magma generation (P. J. Sugden et al., 2019).

Hotspot number 15 (Fig. 4): In the period 45 seconds, a wide Low-velocity anomaly is observed in east and northeast of Lake Lake Van and just east of the Ararat, Sahand, Sabalan, Girkulf, Bitlis Massif, Nakhchivan, Central Armenia, Astara, South Caspian, we argue that it marks a LAB depth of approximately $99 \mathrm{~km}$ and so it has entered the asthenosphere layer. The intrusion (penetration) of hot molten material from the asthenosphere to the lithosphere and the interactions between these two major and important discontinuities at the lithosphereasthenosphere (LAB) boundary to create hotspot No. 15 are not unexpected.

In the period of 55 to 70 seconds (Fig. S7), waves are primarily sensitive to depths between 56.66 to $168 \mathrm{~km}$; namely, the penetration depth is completely at the boundary of the lithosphere and the asthenosphere layers and the highest part (top) of the upper mantle and the average depth is $112.33 \mathrm{~km}$, and so it has penetrated into the asthenosphere layer. The group velocity map shows lateral changes of 1.4 to 5.04 kilometers per second. Long-periods of 50 to $70 \mathrm{~s}$ (approximate depth of $200 \mathrm{~km}$ ) can be considered permanent and stable hot spots. 
Hotspots and areas during periods of 55, 60, 65, and 70 seconds (Fig. S13): At the depths common between the lithosphere-asthenosphere-upper mantle, anomalies accumulation, inhomogeneities, and antagonistic behaviors are usual in surface wave velocity variations. In these areas, due to constant temperature changes due to plate tectonic activity, the effect of active liquids penetrated by the asthenosphere, subsidence, uplifts, hot asthenospheric diapirs intrusion and plumes, surface waves have variable behavior. According to depth-temperature diagrams (e.g. Sugden et al. 2019), at these depths, the onset of dry melting in the convecting mantle and the Spinel out or hard-glassy mineral occurring as octahedral crystals of variable color and consisting chiefly of magnesium and aluminum oxides, and these interactions increase the temperature and stress density contrasts, and as a result, it leads to the creating unexpected velocity anomalies (low or high). However, in the long periods of 50-70 seconds, the hot-cold spots description remains unclear based on our results due to the lack of data (smearing), and further data are required in order to make definitive conclusions on this matter. Further details regarding better understanding the resolution parameters and the hot-cold determination and description using tomography maps in the period of 5 to 70 seconds in a point-by-point are described in the supplementary information file (Figs. S10, S11, S12, S13, S14, S15, and table 3).

\section{Conclusions}

In this paper, the seismic interferometry was applied successfully to construct 2D Rayleigh tomography surface waves velocity maps across the Caucasus territory using local-regional earthquake data. We have presented the first Rayleigh wave group velocity maps across the Caucasus territory using tomography method and determined the Hot-Cold spots of the study area for different periods and depths. These maps show excellent agreement with many of the geological features of the Caucasus territory, such as Volcanoes Complex, Troughs, Uplifts, Basins. Based on tomographic maps in periods of 5 to 70 seconds and geological evidences, were determined and analyzed 15 hot spots (dark red spots) in the study area. The rest of the areas with dark blue and green-yellow-blue colors are cold spots that represent (express) the remnants of an old tectonic plate that has been subducted underneath the Earth plates (large cold and aseismic area during million years).

Tomographic maps with distinct velocities over short-periods of 5 to 30 seconds (equivalent to a depth of 6 to $68 \mathrm{~km}$ ) are more sensitive to the structure of the crust and slightly to the highest part of the lithosphere (pre- lithosphere). These periods represent sediments in the basins, chemical interactions of hydrocarbon resources, molten material and magma chambers beneath volcanoes, and Moho discontinuity which these areas can be considered temporary and unstable hot and cold spots.

In tomographic maps with medium periods of 35 to 50 seconds (equivalent to a depth of 65 to $167 \mathrm{~km}$ ), Azerbaijan, Kura, and South Caspian basins and Talesh heights are covered with highvelocity, which we suggest cold lithosphere roots for these areas. On the contrary, the lowvelocity in the east of the Greater Caucasus, the eastern Black Sea basin, eastern Anatolia and NW Iran are observed with low-velocity, resulting in very thin lithosphere and hot asthenosphere in the region which these areas can be considered temporary and semi-stable hot and cold spots. Long-period tomographic maps velocity structures of 55 to 70 (approximate depth of $200 \mathrm{~km}$ ), ultrahigh-velocity anomalies continue under the South Caspian Basin, Baku, and Kura, and even has been spread to the heights of Talesh, northwestern Iran, and the Bitlis Massif and while a wide area is covered with ultralow-velocity (dark red). We interpret the deep ultrahigh-velocity 
anomalies may be the broken off cold lithosphere generated slabs were sinking into the mantle transition zone and very hot upper mantle with a low mantle lid (cap). Also, the high-velocity in the eastern Greater Caucasus and the Caspian Sea is a part of the subduction system, and asthenosphere with significant amounts of melt is the major factor producing this ultralowvelocity zone in the region which these areas can be considered permanent and stable hot spots.

\section{References}

[1] Wilson, J. Tuzo, A possible origin of the Hawaiian Islands, Canadian Journal of Physics. doi:10.1139/p63-094 (1963).

[2] Dye, S. T. Geoneutrinos and the radioactive power of the Earth. Reviews of Geophysics. 50 (3): RG3007. arXiv:1111.6099. Bibcode:2012Rv Geo..50.3007D. doi:10.1029/2012RG000400. S2CID 118667366 (2012).

[3] Sosson, M., Stephenson, R., Adamia, S., Tectonic Evolution of the Eastern Black Sea and Caucasus, https://doi.org/10.1144/SP428.16 (1977).

[4] Alik Ismail-Zadeh et al., Geodynamics, seismicity, and seismic hazards of the Caucasus, https://doi.org/10.1016/j.earscirev.2020.103222 (2020).

[5] Simon Mcclusky et al., Global Positioning System constraints on plate kinematics and dynamics in the eastern Mediterranean and Caucasus, DOI: 10.1029/1996JB900351 (2000).

[6] Youshun Sun et al., Crustal and uppermost mantle structure of Caucasus and surrounding regions, Doi:10.1007/s1 1589-012-0874-y (2012).

[7] Jackson, J., Priestley, K., M. Allen, and M. Berberian, Active tectonics of the South Caspian Basin, Geophys. J. Int. 148, 214-245 (2002).

[8] Kinahan P, Townsend D., Attenuation correction for a combined 3D PET/CT scanner, Med Phys., https://opentextbc.ca/geology/chapter/ 9-1-understanding-earth-through-seismology/ (1998).

[9] Ditmar, P. G., and Yanovskaya, T. B., Generalization of Backus-Gilbert method for estimation of lateral variations of surface wave velocities: Phys. Solid Earth, Izvestia Acad. Sci. USSR, 23 (6), 470-477 (1987).

[10] Yanovskaya, T.B. \& Ditmar, P.G., Smoothness criteria in surface wave tomography. Geophys. J. Int., 102, 6372 (1990).

[11] Backus, G.E. \& Gilbert, F., The resolving power of gross earth data, Geophys. J. 16, 169-205 (1968).

[12] Lihua Fang et al., Rayleigh wave tomography in North-China from ambient seismic noise (2008).

[13] R. Jrbashyan et al., Geology of Meso-Cenozoic Basins in Central Armenia, with Comment on Indications of Hydrocarbons, (2001).

[14] Milanovski, E.E., Sevan Basin. In: Geology of Armenian SSR, v. 1, Geomorphology, Ar. Ac. Sci. Publ., Yerevan, 1962, p. 115-136 (in Russian), (1962).

[15] Özgür Karaoğlu et al., volume lava flows fed by a deep magmatic reservoir at Ağrı Dağı (Ararat) volcano, Eastern Turkey, DOI: 10.1007/s00445-016-1098-0 (2017).

[16] Vural Oyan, Geochemical and petrologic evolution of Otlakbaşı basaltic volcanism to the east of Lake Van, DOI: $10.19111 /$ bulletinofmre.427782 (2018).

[17] Mehraj Aghazadeh et al., The gabbro (shoshonitic)-monzonite-granodiorite association of Khankandi pluton, Alborz Mountains, NW Iran, DOI: 10.1016/j.jseaes.2010.01.002 (2010).

[18] Sosson, M., et al., Sedimentary Basin Tectonics from the Black Sea and Caucasus to the Arabian Platform, http://dx.doi.org/10.1144/SP340.14 0305-8719/10 (2010).

[19] P. J. Sugden et al., The Thickness of the Mantle Lithosphere and Collision-Related Volcanism in the Lesser Caucasus (2019).

\section{Acknowledgments}

Thanks to the Iranian Seismological Center, Incorporated Research Institutions for Seismology (IRIS) Data Management Centre, Iranian National Seismological Network, National StrongMotion Network of Turkey (TR-NSMN), National Seismic Network of Turkey (DDA), National Seismic Network of Azerbaijan, and National Seismic Network of Georgia who provided some of the seismic data used in this study. Many of the figures in this paper were prepared using GMT (Wessel \& Smith 1995), which thank them. We also thank the Institute of Geophysics of 
the University of Tehran, which managed and supported this study in the framework of the educational mission (2016-2018).

\section{Author contributions}

S.H.A. designed research, gathered, prepared and analyzed data and wrote and executed computer code under the supervision of H.R. and J.K.K. and E.G. are also supervisor and advisor of the study. All authors contributed to discussions and interpretation of geological-geodynamic of the region and S.H.A. after final discussions with H.R., J.K.K. and E.G. wrote the paper.

\section{Competing interests}

The authors declare no competing interests. 


\section{Supplementary Files}

This is a list of supplementary files associated with this preprint. Click to download.

- NewSupplementaryTheCaucasusTerritoryHotColdSpotsDeterm.pdf 